https://www.journal-imab-bg.org

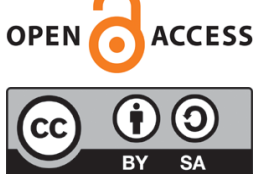

Original article

\title{
SEM EXAMINATION OF MICROMORPHOLOGY CHANGES OF INTRACANAL DENTINE AFTER TREATMENT WITH DIODE LASER
}

\author{
Elka Radeva ${ }^{1}$, Mihail Tarassov ${ }^{2}$, Evgenya Popova ${ }^{1}$, Raya Grozdanova ${ }^{1}$, Dimitar \\ Kosturkov $^{1}$, Tsonko Uzunov ${ }^{1}$ \\ 1) Department of Conservative Dentistry, Faculty of Dental Medicine, Medical \\ University, Sofia, Bulgaria \\ 2) Institute of Mineralogy and Crystallography, Bulgarian Academy of Sciences, \\ Sofia, Bulgaria.
}

SUMMARY:

Introduction: In recent years, diode lasers have been increasingly used in endodontics. They are applied after the mechanical treatment of the root canal and lead to various thermal and micromorphological changes in the root canal dentin. For this laser application, different types and designs of optical fibers are developed to improve the spread of laser light.

Purpose: The aim of our in vitro study is to identify and classify with scanning electron microscopy (SEM) the morphological changes in the root canal dentin that occur after exposure to diode laser irradiation using two types of optical fibers.

Material and Methods: The root canals of 48 freshly extracted teeth are prepared with Pro Taper Gold to F3 and treated with $810 \mathrm{~nm}$ diode laser for $8 \mathrm{~s}$ with helicoidal withdrawing motion of the laser tip from the apical to the coronal part of the tooth. Teeth are divided into three groups: the first is laser irradiated using quartz fiber, the second is laser irradiated using organically modified quartz fiber, and the third is the reference group without laser treatment. All teeth are prepared for scanning electron microscopy.

Results: Micromorphological changes of the root canal dentin in the coronal, middle and apical parts of the root canal are found in SEM. Partially melted dentine is observed as thin films covering the entire surface with dentine tubules. The melting effect on the micromorphology of the root canal walls distinctly increases from the coronal to the apical part of the root canal.

Conclusion: The SEM study shows that diode laser irradiation with a wavelength of $810 \mathrm{~nm}$ causes sealing of the dentinal tubules. This effect is more pronounced when using quartz optical fiber.

Key words: diode laser, micromorphological changes, optical fiber, SEM

\section{INTRODUCTION}

Successful endodontic treatment depends largely on the removal of microorganisms from the root canal system, which is mainly carried out with biomechanical treatment of the root canal. Studies have shown that the complete removal of microorganisms and their toxins is almost impossible. More than $35 \%$ of the root surface remains untreated after the use of mechanical instrumentation [1]. Bacteria can penetrate approximately half the distance between the wall of the root canal and the cement-dentine border. This necessitates the use of additional agents to remove the smear layer and affect the microorganisms in the dentinal tubules $[1,2]$. In recent years, researchers have been focusing on high-energy diode lasers with a wavelength of $810 \mathrm{~nm}$ to $1064 \mathrm{~nm}$ as an additional method of action in endodontic treatment. The diode lasers have good technical characteristics - they radiate over a wide range of electromagnetic spectrum, have the ability to combine different resonance frequencies and wavelengths, as well as ergonomic, durable and affordable $[3,4,5,6]$.

In endodontics, the diode laser is applied to the root canal after its preconditioning, which ensures the unobstructed fiber movement. Despite the optimization of the laser tips, there are some limitations related to their intracanal use. The emission of the laser radiation is directed vertically along the length of the optical fiber and it is almost impossible to obtain uniform coverage of the root surface. In addition, the depth of laser light propagation is important, since the light can pass beyond the apical opening and affect the periapical tissues. Thermal damage to the root and surrounding tissues is possible $[7,8]$.

To improve the direction of laser light distribution in the root canal, laser tips with lateral radiation have been developed. Conical end may be designed on the basis of glass (quartz), including those doped with fluoride, germanium or gallium, using a pipe etching process to obtain increased lateral emissions. Such tips deliver more laser energy to the walls of the root canal than to the apical part of the tooth. The tapered tips turn out to be better than the conventional tips for removing thick debris layers [9].

The application of laser systems to narrow and curved root canals is difficult [10]. The development of very thin and flexible optical fibers allows easier application of lasers in the root canal [11].

The aim of our in vitro study is to identify and clas- 
sify with scanning electron microscopy (SEM) the morphological changes in the root canal dentin that occur after exposure to diode laser irradiation using two types of optical fibers.

\section{MATERIAL AND METHODS}

Preparation of extracted teeth

The selected teeth were examined with diagnostic XRay and then autoclaved. The coronal parts of teeth were removed with diamond bur to a standard tooth length of 15 $\mathrm{mm}$.

The root canals were cleaned and prepared with ProTaper Gold to F3 (fig. 1). The final irrigation was made with $5.25 \%$ sodium hypochlorite and $17 \%$ EDTA.

Fig. 1 a, b. X-rays before (a) and after cleaning and shaping the root canal with ProTaper Gold (b)
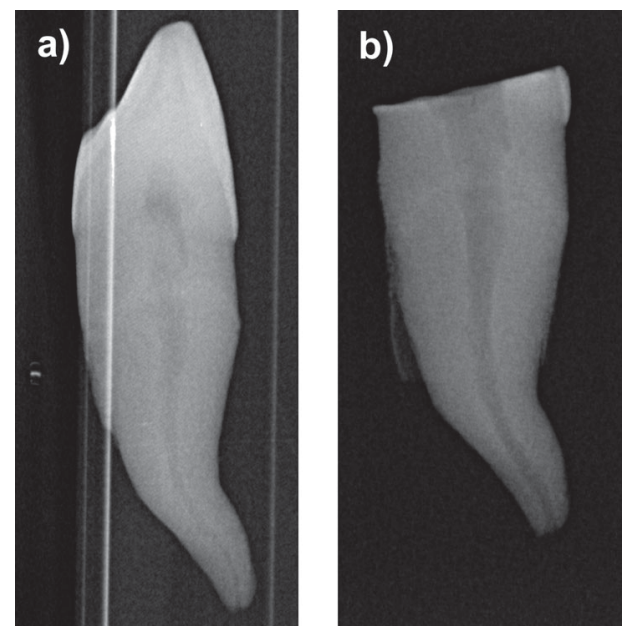

The root canals were then treated with a diode laser having a wavelength of $810 \mathrm{~nm}$ and using an optical fiber with a 400 ìm diameter.

The optical fiber was inserted into the root canal to a depth of $13 \mathrm{~mm}$ ( $2 \mathrm{~mm}$ shorter than the entire length of the root canal) and then the laser treatment was performed for 8 $\mathrm{s}$ with helicoidal withdrawing motion from the apical to the coronal part of the tooth.

After mechanical and chemical treatment of the root canals, the teeth were divided into three groups: two groups were then laser treated with two different type of light conductor (optical fiber), and the third group was a control. As a light source, a DenLase $810 \mathrm{~nm}$ diode laser was used in the two experimental groups (fig. 2).
Fig. 2. Diode laser "DenLase"

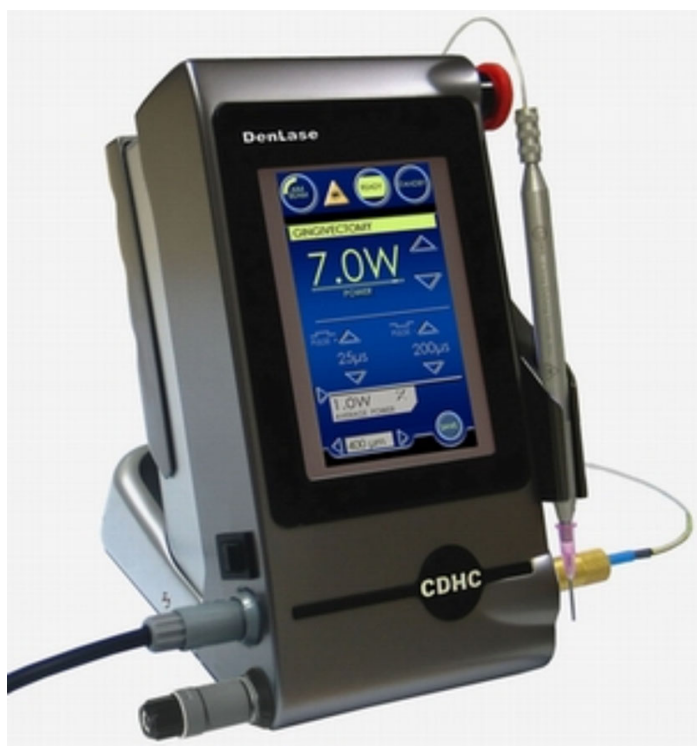

First group (quartz light conductor) - 18 teeth. Maximum allowable power - $1 \mathrm{~W}$.

Second group (organic modified quartz optical fiber) - 18 teeth. Maximum allowable power $1 \mathrm{~W}$.

Control group - 12 teeth, mechanical and chemical treatment with ProTaper Gold, without treatment with laser.

After mechanical and chemical shaping, the root canals were finally irrigated with $5 \mathrm{ml}$ of $5.25 \% \mathrm{NaOCl}, 5 \mathrm{ml}$ of distilled water and $2 \mathrm{ml}$ of $17 \%$ EDTA and then dried with paper points.

After exposure to a DenLase $810 \mathrm{~nm}$ diode laser, the teeth were cut in the vestibular-lingual direction for observation with a scanning electron microscope (SEM) (fig. 3).

Fig. 3. ZEISS EVO LS25 scanning electron microscope

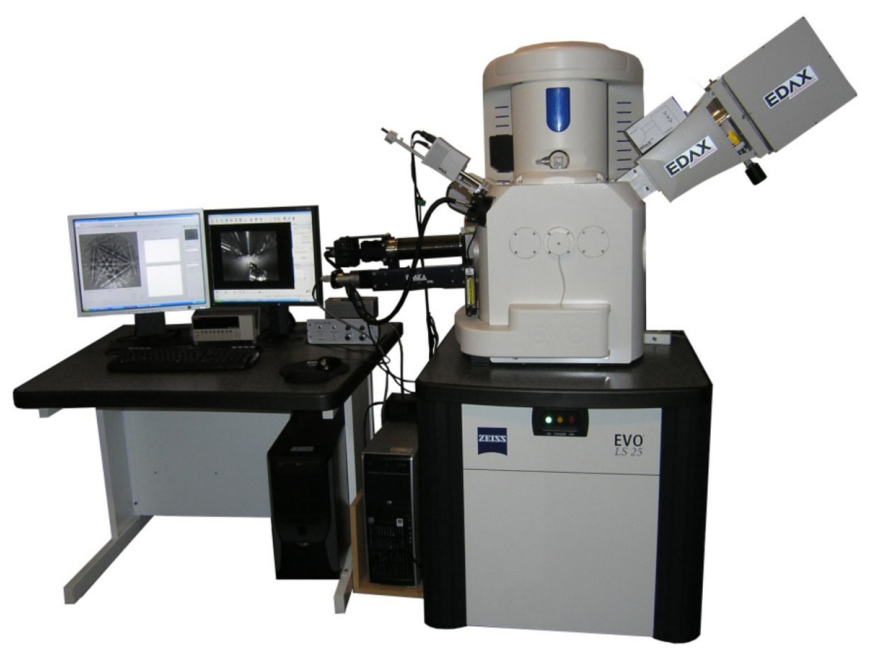

Prepared teeth were mounted on SEM holders (fig. 4) using a conductive glue, then coated with gold using Edwards Sputter Coater S150B (fig.4). Micromorphology of intracanal dentin was examined on a ZEISS EVO LS25 scanning electron microscope in secondary electron mode at an acceleration voltage of $18 \mathrm{kV}$ and magnifications between x54 and x6000. 
Fig. 4. SEM holders with mounted prepared teeth

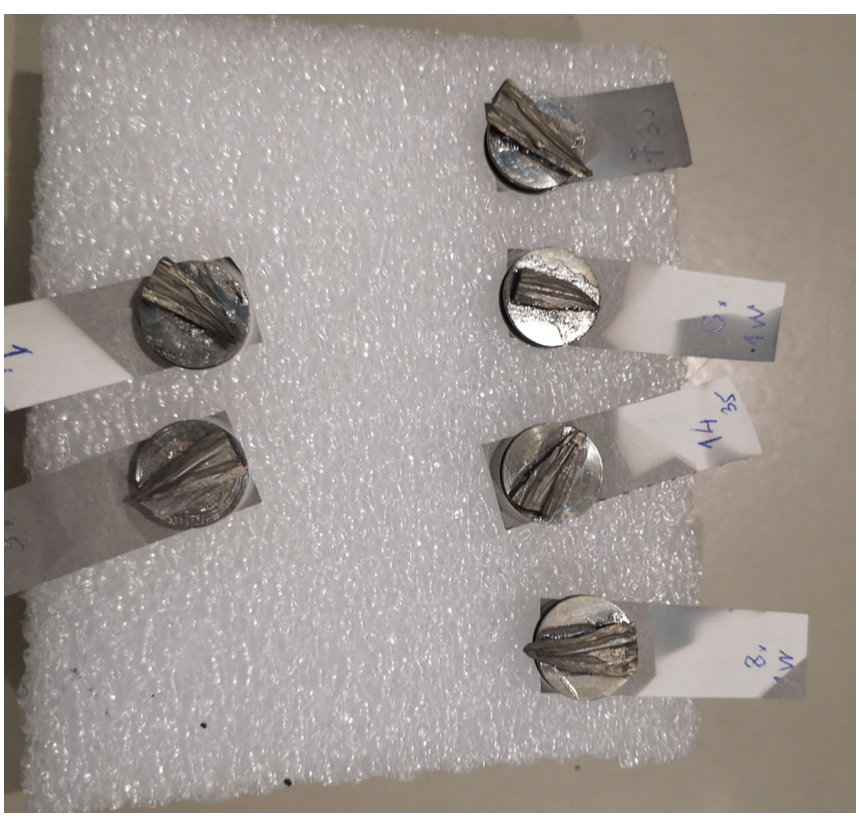

The inner root surfaces were examine in the SEM for the presence and extent of removal of the pollutant layer, as well as for the presence and extent of opening of the dentinal tubules.

\section{RESULTS}

SEM investigation of the root canal dentin was performed in the coronal, middle and apical parts of the root. The results are illustrated in fig. 5 - 14 .

Figure 5 shows that as a result of laser treatment, the material of the root canal is partially melted, forming a thin film covering the entire surface with dentin tubules. The film is very thin and bursts cracks right above the tubules, which are outlined as shining areas. The burst crack formation is secondary and occurs inside the SEM chamber at a very high vacuum $\left(\sim 10^{-7} \mathrm{mbar}\right)$, as the film seals air that emits in high vacuum. The morphology of cracks well follows the tubule cross sections - they are nowhere near perfect round (fig.5).

Fig. 5. SEM image of the coronal part of the root after laser treatment with a quartz light conductor (x3000)

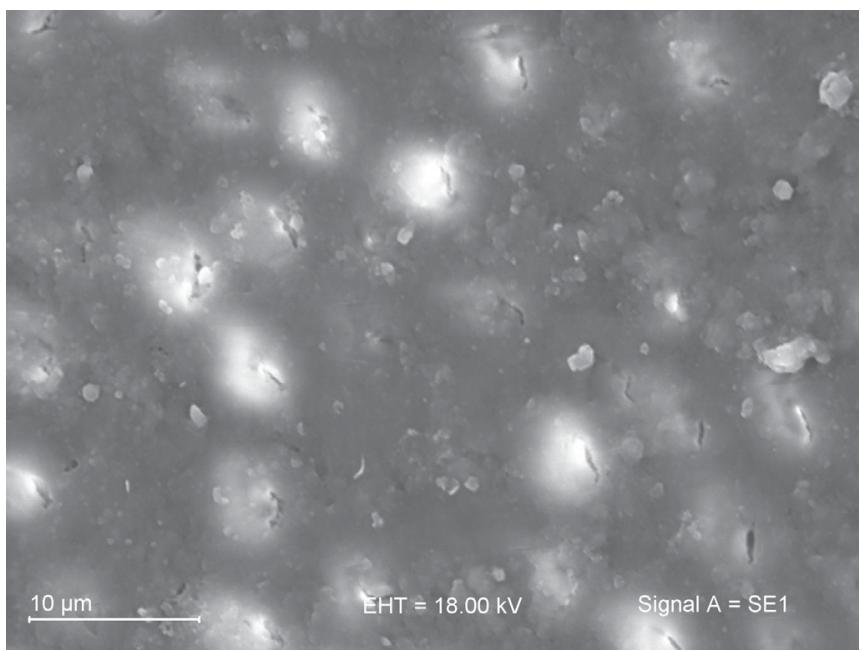

In the middle of the root canal there is much more intense impact of laser radiation - the melted material is much thicker and completely covers and masks the dentinal tubules. The molten material does not form a homogeneous layer and contains obvious signs of recrystallization grained character, angular forms of individual grains and grouping them into grain aggregates (fig. 6).

Fig. 6. SEM image of the middle part after laser treatment with a quartz light conductor (x3000)

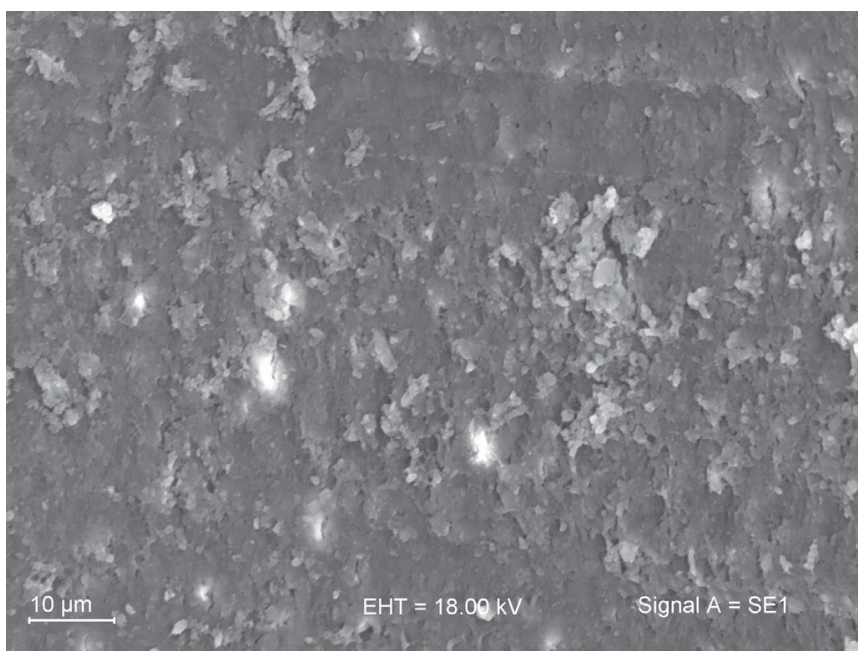

The apical part of the root canal is a molten dentin surface with full occlusion sealing of the dentinal tubules. The molten material unevenly covers the surface of the root canal. It is thick with signs of both recrystallization (angular rains forming aggregates) and preservation of glass-like solidified molten material (rounded shapes) (fig. 7).

Fig. 7. SEM image of the apical part after laser treatment with a quartz light conductor (x3000)

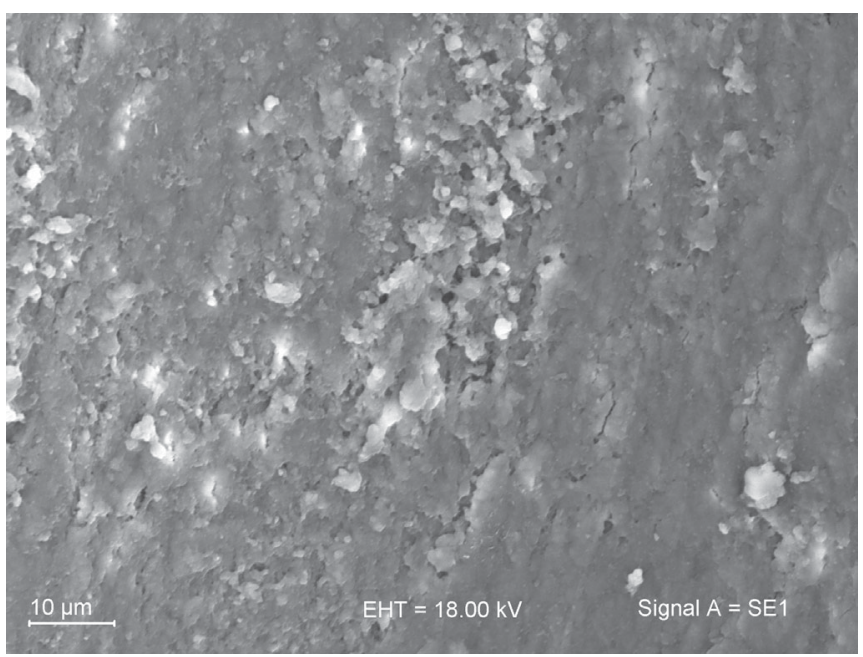

Partially closed dentin tubules are non-uniformly coated with gel-like material. The latter material very tightly seals the tubules (fig. 8 and fig.9). 
Fig. 8. SEM image of the coronary part after laser treatment with an organically modified quartz light conductor (x3000)

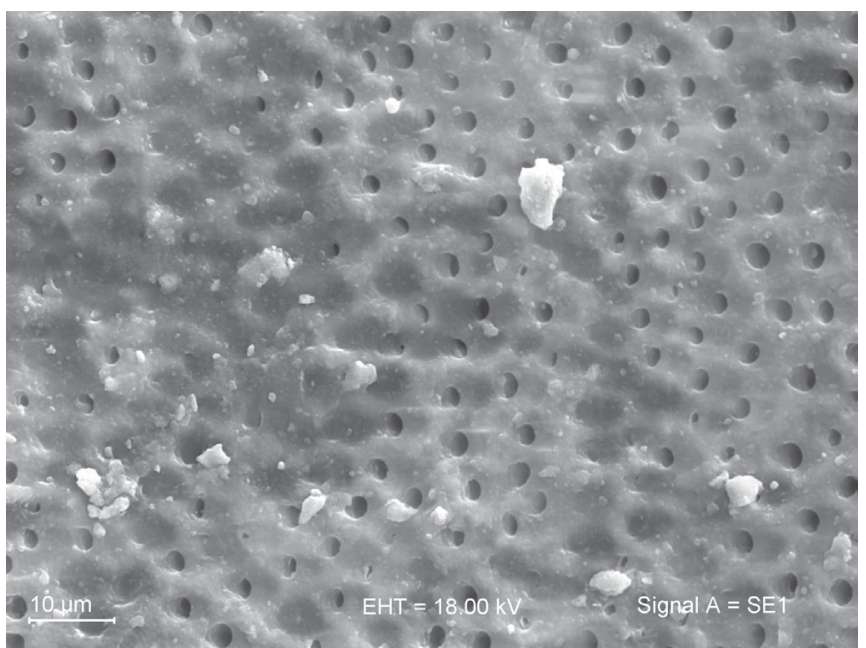

Fig. 9. SEM image of the middle part after treatment with an organically modified quartz light conductor (x3000)

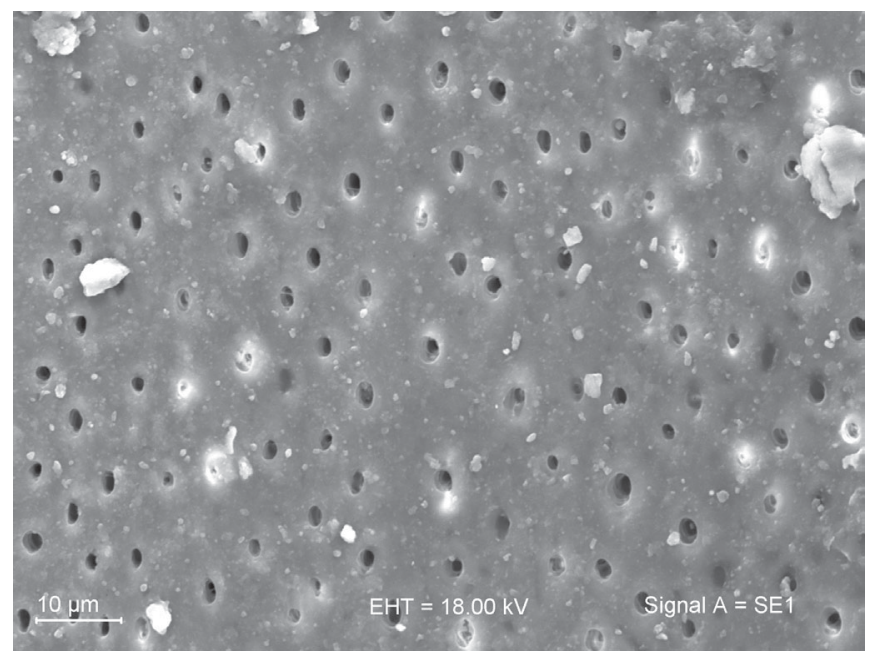

It is assumed that the reduction of the visible dentine tubules is due to the partial melting of the material (fig. 10 and fig. 11).

Fig. 10. SEM image of the apical part after treatment with an organically modified quartz light conductor (x3000)

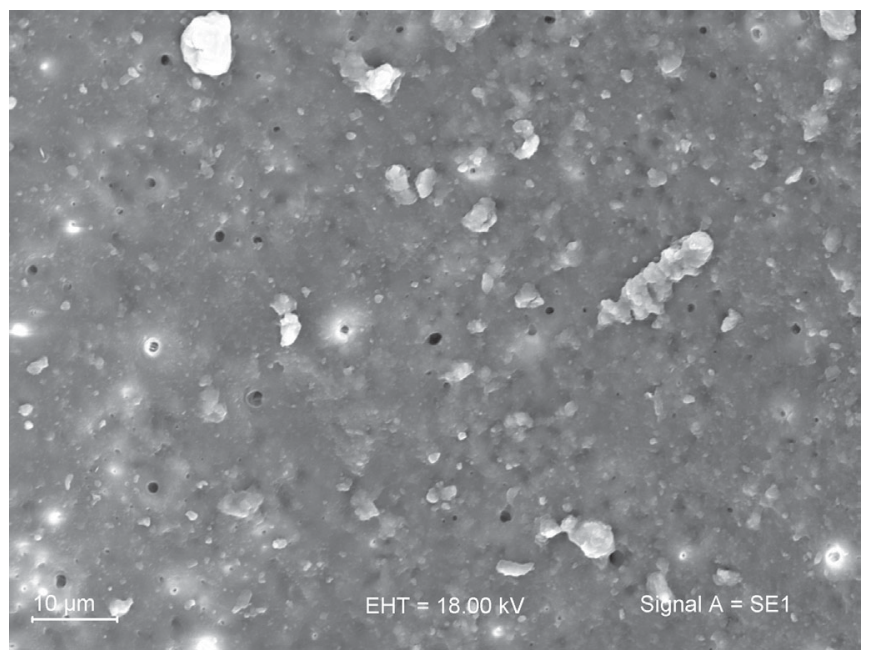

Fig. 11. SEM image of the apical part after treatment with an organically modified quartz light conductor (x3000)

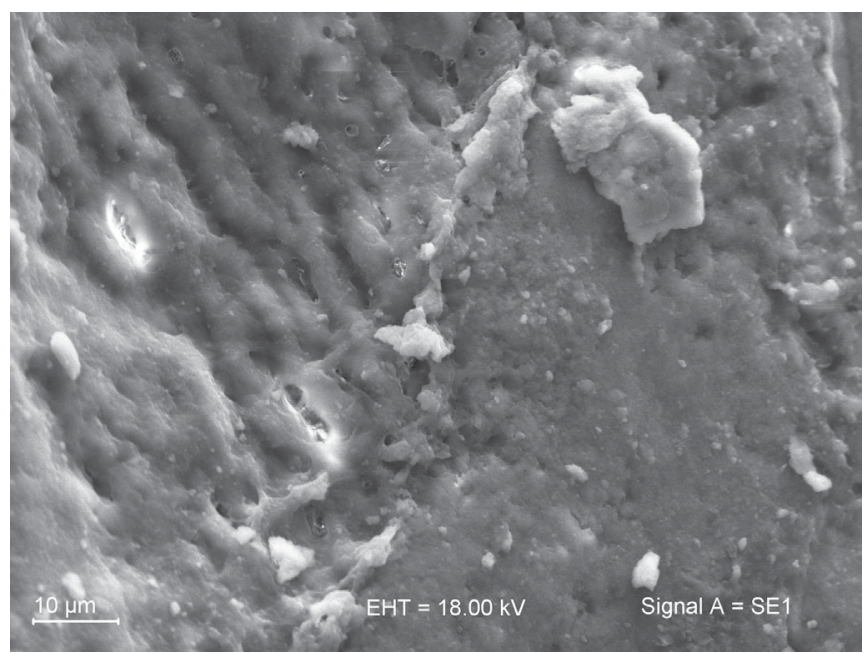

Uneven melting of the dentine and separation of the glass part are observed.

In the control group, without laser treatment, SEM reveals open dentinal tubules and sporadic residues after mechanical treatments of root canal - fragments (debris) to 4050ìm in size and containing $\mathrm{Ca}$ and P. Gel-like layers are also observed as a by-product of washing dentine with a solution.

This material (darker areas in fig. 12) covers a part of the dentine tubules.

Fig. 12. SEM image of the coronary part after the root canal preparation of the control group (x3000)

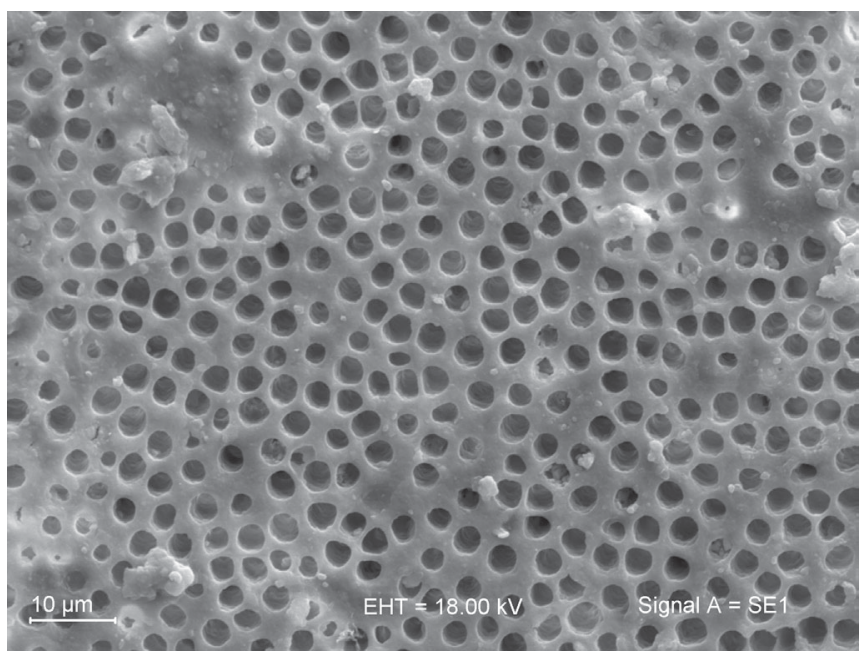

The glowing areas in Fig. 13 correspond to dentinal tubules containing particles loosely attached within the tubules.

In the middle part of the root canal there is a partial crystallization / filling of the dentinal tubules with a material - product of interaction of the washing solution with the dentin. The observed glowing in secondary electrons image of a part of the channels is associated with incomplete contact or adhesion of these crystals / particles with the main dentine matrix (fig. 13). 
Fig. 13. SEM image of the root canal after preparation of the control group (x3000)

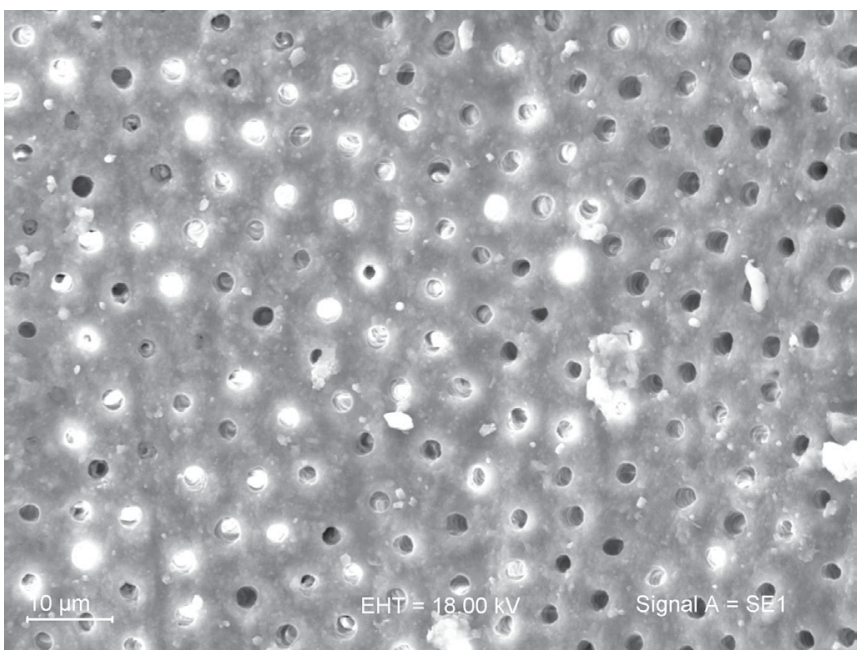

In the apical part of the root canal there is an uneven distribution of the dentinal canals by size, amount and density. Their size ranges from $0.5 \mathrm{ìm}$ to 8ìm. Large canals result from the merging of several smaller canals and are most likely the result of the action of the wash solution effect (fig. 14).

Fig. 14. SEM image of the apical part after the root canal preparation of the control group (x3000)

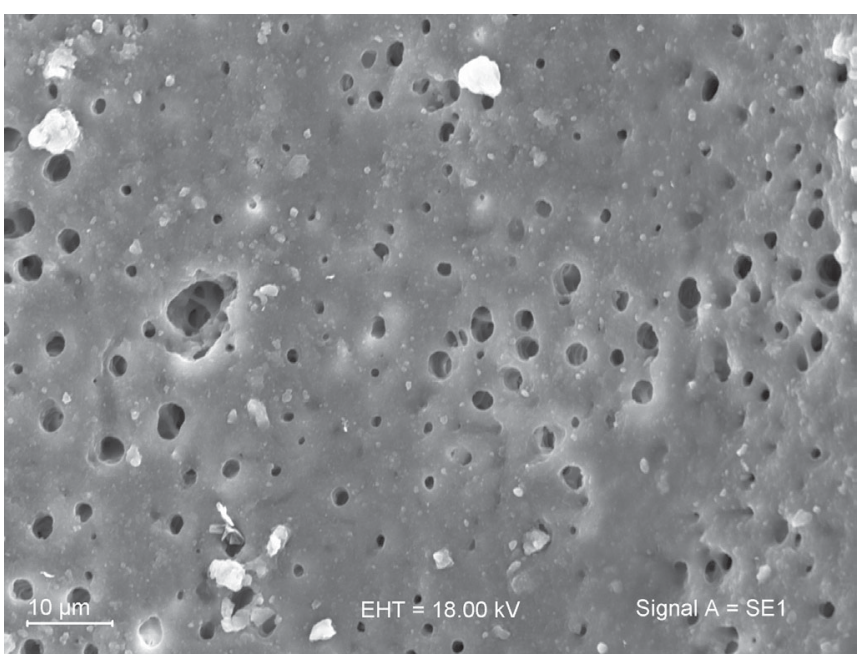

\section{DISCUSSION}

Laser irradiation with the appropriate parameters vaporizes the smear layer and the organic structure of the dentin (collagen fibers), which is characterized by superficial fusion of the dentinal tubules.

Jhingan et al. examined on scanning electron microscope the dentin on the root surface after exposure to a diode laser at $980 \mathrm{~nm}$ and found partial or nearly complete occlusion of the dentinal tubules and melting the intertubular dentin, making the dentin surface smooth with a wellremoved smear layer. This reduces dentin permeability [12] Similar results have been reported by other authors who observed melting and recrystallization of limited areas of the root canal dentin $[6,13,14]$.
Other authors also investigate this problem accenting on the presence of melting and carbonization of the root canal dentin $[12,15]$.

According to the present SEM investigation, melting and fusion distinctly occurs in the apical regions. In the middle areas, only a partial sealing of the tubules was observed, probably because there was less fiber contact with dentin walls, as the canal was wider than the apical area where the laser energy was more concentrated. This observation is also made by Ribeiro et al. [16], which investigate the morphological changes in the root dentin after applying a $810 \mathrm{~nm}$ diode laser with three different powers. At the power relatively equal to that used by us $-1.25 \mathrm{~W}$, the results are similar.

The relationship between the size of the optical fiber and its contact with the root surface and the degree of melting and recrystallization of the canal dentin was also found using the Er: YAG laser and Er; Cr: YSGG laser [17, 18].

Morphological changes were observed in the apical part of the root after intracanal irradiation with a high energy diode laser, consisted in the presence of well-cleaned dentin surfaces of the root canal with sealed dentinal tubules at localized sections showing melting and recrystallization $[12,13]$.

Light conductor movement in the root canal is important for contact with the root walls, and the thermal and morphological effects of the laser action depend on it.

The organically modified light conductor used by us is more flexible than conventional quartz light conductor and its contact with dentine walls is reduced.

This explains the smaller morphological changes in the root canal dentin in the second teeth group. El-Zohairy A. et al. emphasize the mandatory condition for the laser application - the circular motion of the optical fiber from the apex to the coronary part and vice versa, thus reducing and avoiding the melting of the dentine and the transfer of the thermal effect on the periodontal tissues [19].

In general, infrared wavelengths, such as $980 \mathrm{~nm}$ and $1064 \mathrm{~nm}$, can cause fusion and recrystallization on the dentin surface, resulting in dentinal tubular closure [13, 20].

In conclusion, it can be said that the literature mainly deals with the antibacterial effect, the sealing of the dentinal tubules and the increase of the temperature on the root surface. Different in vitro and in vivo studies confirm to varying degrees the antibacterial effect of the diode laser depending on the microorganisms considered by the study. All available studies with an electron microscope confirm the effect of "sealing the dentinal tubules". The effect of high energy diode lasers in endodontics continues to be investigated because of the controversial data on morphological changes and the thermal effect on dentin under different application conditions.

\section{CONCLUSIONS}

After exposure to an $810 \mathrm{~nm}$ diode laser, sealing of dentinal tubules is observed in SEM images, more pronounced using the quartz light conductor. The organically modified light conductor used by us is more flexible than standard quartz light conductor is, and its contact with dentine walls is reduced, resulting in fewer morphological changes in the root canal dentin as observed in SEM. 


\section{Acknowledgments:}

The study is conducted under Contract No. D-88/03.05.2018, CMS, MU-Sofia.

\section{REFERENCES:}

1. Bhatia S, Kohli S. Lasers in Root Canal Sterilization - A Review. Int J Sci Study. 2013 Oct-Dec;1(3):107-111.

2. Castelo-Baz P, Martín -Biedma B, Ruíz-Piñón M, Rivas- Mundiña B, Bahillo J, Seoane-Prado R, et al. Combined Sodium Hypochlorite and 940 nm Diode Laser Treatment Against Mature E. Faecalis Biofilms in-vitro. $J \mathrm{La}$ sers Med Sci. 2012 Summer;3(3):116121. [Crossref]

3. Marchesan MA, Brugnera-Junior A, Souza-Gabriel AE, Correa-Silva SR, Sousa-Neto MD. Ultrastructural analysis of root canal dentine irradiated with 980-nm diode laser energy at different parameters. Photomed Laser Surg. 2008 Jun;26(3):235-240. [PubMed][Crossref]

4. Coluzzi DJ, Convissar RA. Atlas of Laser Applications in Dentistry. 1st Edition. Quintessence Pub Co. January 30, 2007. pp.1-7.

5. Renk KF. Basics of Laser Physics. For Students of Science and Engineering. Springer. 2012, XVIII, Chapter 02 pp. 17-26. [Crossref]

6. Saydjari Y, Kuypers T, Gutknecht N. Laser Application in Dentistry: Irradiation Effects of Nd:YAG $1064 \mathrm{~nm}$ and Diode $810 \mathrm{~nm}$ and $980 \mathrm{~nm}$ in Infected Root Canals-A Literature Overview. Biomed Res Int. 2016;2016:8421656. [PubMed] [Crossref]

7. Al-Karadaghi TS, Gutknecht N, Jawad HA, Vanweersch L, Franzen R. Evaluation of Temperature Elevation During Root Canal Treatment with Dual Wavelength Laser: $2780 \mathrm{~nm}$ Er,Cr:YSGG and $940 \mathrm{~nm}$ Diode. Photomed Laser Surg. 2015 Sep;33(9):

\section{0-6. [PubMed] [Crossref]}

8. Beer F, Farmakis ET, Kopic J, Kurzmann C, Moritz A. Temperature Development on the External Root Surface During Laser-Assisted Endodontic Treatment Applying a Microchopped Mode of a $980 \mathrm{~nm}$ Diode Laser. Photomed Laser Surg. 2017 Apr;35(4): 206-212. [PubMed] [Crossref]

9. George R, Meyers IA, Walsh LJ. Laser activation of endodontic irrigants with improved conical laser fiber tips for removing smear layer in the apical third of the root canal. $J$ Endod. 2008 Dec;34(12):1524-7. [PubMed] [Crossref]

10. Matsumoto K. Lasers in endodontics. Dent Clin North Am. 2000 Oct;44(4):889-906, viii. [PubMed]

11. Moritz A, Schoop U. Lasers in Endodontics. In: Oral Laser Application. Moritz A. (Ed.) 1st Edition. Quintessence Publishing, Germany. 2006. Chapter 06. pp.241-313.

12. Jhingan P, Sandhu M, Jindal G, Goel D, Sachdev V. An in-vitro evaluation of the effect of $980 \mathrm{~nm}$ diode laser irradiation on intra-canal dentin surface and dentinal tubule openings after biomechanical preparation: Scanning electron microscopic study. Indian $J$ Dent. 2015; 6(2):85-90. [Crossref]

13. Saraswathi MV, Ballal NV, Padinjaral I, Bhat S. Ultra morphological changes of root canal dentin induced by $940 \mathrm{~nm}$ diode laser: An invitro study. Saudi Endod J. 2012; 2(3): 131-5. [Crossref]

14. Juriè IB, Aniæ I. The Use of La- sers in Disinfection and Cleanliness of Root Canals: a Review. Acta Stomatol Croat. 2014; 48(1):6-15. [PubMed] [Crossref]

15. Al-Karadaghi TS, Franzen R, Jawad HA, Gutknecht N. Investigations of radicular dentin permeability and ultrastructural changes after irradiation with Er,Cr:YSGG laser and dual wavelength (2780 and $940 \mathrm{~nm}$ ) laser. Lasers Med Sci. 2015 Nov;30(8):2115-21. [PubMed] [Crossref]

16. da Costa Ribeiro A, Nogueira GE, Antoniazzi JH, Moritz A, Zezell DM. Effects of diode laser $(810 \mathrm{~nm})$ irradiation on root canal walls: thermographic and morphological studies. $J$ Endod. 2007 Mar;33(3):252-5. [PubMed] [Crossref]

17. Karlovic Z, Pezelj-Ribaric S, Miletic I, Jukic S, Grgurevic J, Anic I. Erbium:YAG laser versus ultrasonic in preparation of root-end cavities. $J$ Endod. 2005 Nov;31(11):821-3. [PubMed] [Crossref]

18. Altundasar E, Ozcelik B, Cehreli ZC, Matsumoto K. Ultramorphological and histochemical changes after ER,CR:YSGG laser irradiation and two different irrigation regimes. $J$ Endod. 2006 May;32(5):465-8. [PubMed] [Crossref]

19. El-Zohairy A, Serageldin RF. Synopsis is Using Dental Diode Laser in Endodontic. EC Dental Science. 2016 Nov; 5(4):1139-1144. [Internet]

20. Camargo SC. The antibacterial effects of lasers in endodontics. Roots. 2012; 1:6-9.

Please cite this article as: Radeva E, Tarassov M, Popova E, Grozdanova R, Kosturkov D, Uzunov T. SEM examination of micromorphology changes of intracanal dentine after treatment with diode laser. J of IMAB. 2019 Oct-Dec;25(4):27232728. DOI: https://doi.org/10.5272/jimab.2019254.2723

Received: 25/05/2019; Published online: 08/10/2019

Address for correspondence:

Assoc. Prof. Elka Radeva, DMD, PhD

Department of Conservative dentistry Faculty of Dental Medicine, Medical University - Sofia,

1, Georgi Sofiyski Blvd., 1431 Sofia, Bulgaria.

E-mail: eliradeva@abv.bg 